\title{
An Analysis of Dai Brocade Pattern and Application Innovation in Denim Garment
}

\author{
Cheng Yu ${ }^{1}$, Liang Huie ${ }^{1,2^{*}}$, Du Bingbing ${ }^{3}$, S M Minhus ${ }^{1}$ \\ 1. College of Textiles \& Clothing, Jiangnan University, No. 1800 Lihu Avenue, Wuxi 214122, China \\ 2. Wuxi Vocational and Technical College of Technology, Wuxi, Jiangsu 214206, China \\ 3. Beijing Institution of Fashion Technology, No. 2, East Sakura Street, Chaoyang District, Beijing \\ * E-mail of the corresponding author: lianghe@jiangnan.edu.cn
}

\begin{abstract}
This research is financed by "2019 Graduate research innovation program project of Jiangnan university" (2019 JNKY19-035; “Major Projects of Philosophy and Social Sciences in Jiangsu Universities” (2019STZDA02)
\end{abstract}

\begin{abstract}
The Dai brocade has a long history, unique craftsmanship, simple and unique style. It has bright colors, strong contrasts, and exquisite patterns, with unique national art and cultural colors. This article expounds the artistic form of the brocade pattern from the subject matter of the pattern, analyzes its artistic aesthetics, cultural connotation, and visual symbols. Attempting to apply the Dai brocade pattern to the design of denim women's clothing. The results show that the combination of traditional Dai brocade patterns and modern denim elements can leading denim clothing a more diversified and international charm
\end{abstract}

Keywords: The Dai ethnic Brocade Pattern; denim; fashion design; art; national culture

DOI: $10.7176 / \mathrm{ADS} / 80-06$

Publication date: February $29^{\text {th }} 2020$

\section{Introduction}

The Dai people's brocade, on the Shen Guo textile reserve unearthed from the Shizhai Mountain in Jinning, has the figure of the Dai ancestor's textiles (Qing, 2009). It is recorded in "Records of the Grand Historian", "Han history" and "Book of later Han" that the character "Brocade" is composed of two characters "Gold" and "silk" to represent the noble silk fabric like gold. As mentioned in "Shiming-Shicai": Brocade, Gold also, the process is multifarious and its price is as high as gold (Maolan). There are abundant sources of brocade, of which cotton, silk, kapok, linen, wool, etc. are the main raw materials of brocade. Cotton and silk fibers are usually used, and in the traditional brocade, the silk-cotton mixed brocade accounts for the majority. The brocade is widely used in the family's bed linen, bedding, tube skirt, backpack, Buddhist altar, and other items to beautify and decorate life. The origin of the minority nationality in Yunnan has a long history, and its ethnic culture is colorful. The brocade pattern of the Dai nationality is one of the representative characteristics of the culture, which is the lifelong craftsmanship of Dai women. It has a certain reference value to the current stylization of clothing design.

As a very important category in the clothing classification, since the birth of the first denim in the 19th century, it has experienced a century of baptism. It has become a "fashion darling" because of its durability, variability, and wide practicality. This paper attempts to combine Brocade designs with women's denim clothing to explore the inheritance of traditional craftsmanship and fashion beauty and promote the diversity of denim women's styles.

\section{Overview of Dai brocade}

2.1 Definition of Dai brocade

Dai brocade is one of the minority brocades, commonly known as "Saroo". Dai brocade is an ancient textile technique. The design of the pattern is created by skilled textile techniques. Most of them are single-faced, and wet-line are used to make a pattern, the organization of the pattern had a high-quality requirement (Yi \& Yuan, 2007). Traditional brocade is divided into two types: cotton brocade and silk brocade. Cotton brocade usually uses through-weft. Silk brocade has both through-weft and weft-break. With the development of society and the 
improvement of technology, in addition to cotton brocade and silk brocade, there are more silk and cotton mixed brocade, cotton, and linen mixed brocade, etc. And brocades of different materials have also been recognized and accepted by society, so that they are applied to clothing, hanging decorations, accessories, artwork and other multi-directional uses. Its exquisite craftsmanship, themes, decorative patterns, colorful colors, and distinctive national characteristics are the crystallization of the Dai people 's aesthetic concepts and technical labor for thousands of years, has the very high art appreciation value (as shown in figure 1)

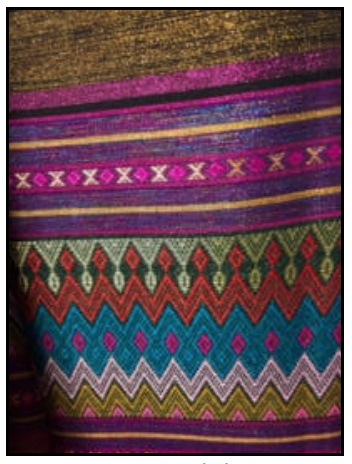

(a)

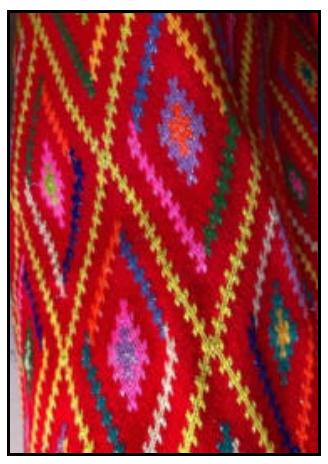

(b)

Figure 1. Physical figure about Dai brocade (taken at the Dehong ethnic clothing store in Mangshi)

Dai brocade is the important embodiment of the Dai nationality culture, the artistic aesthetics of Da brocade are closely related to the living environment and production methods of Dai people. Its development process has gradually evolved from the most primitive shelter and warming function to the spiritual sacrifice of Buddhist life. It has produced a variety of patterns and forms, experienced a process of rising from practical life, artistic culture to spiritual enrichment, and played a very important role in the life of the Dai people.

\subsection{Classification of Dai brocade patterns}

Design refers to the pre-design of practical art, architectural art and decorative art in the aspects of modeling, color, and organizational structure, and the design made under the restriction of technological materials, uses, economy and production conditions, and the general designation of decorative patterns (Yaohua, 1997). The brocade pattern is formed by the interlacing of warp and weft threads and the interlacing of color threads through a diagonal loom. Its patterns mainly come from all aspects of life, mostly based on objective nature, and return to the essence of life. As a result, it evolves and expands to form new cultural forms and artistic effects. The variety is colorful and fantastic. According to the pattern composition and artistic style of the brocade pattern, there are six main categories: plant patterns, animal patterns, person patterns, geometric patterns, architectural patterns, and comprehensive patterns.

\subsubsection{Plant pattern}

Plant patterns are a relatively large proportion of the Dai brocade patterns. The main inspiration is that life is closely related to people's lives. For example, Erythrina flowers, Star anise flowers, Ginger flowers, Big iris flowers, "Hong Mao" flowers, lotus flowers, plantain flowers, fennel flowers, etc., are all common plants in the tropical rainforest areas where the Dai people live. Among them, the linden tree is also a common pattern on the brocade, especially on the Buddha. The Bodhi tree is a Buddha tree in people's hearts, which symbolizes sacredness, auspiciousness, and nobility, and is highly respected by the Dai people. These plant patterns truly reproduce the living environment and religious beliefs of the Dai people and express the Dai people's love of beauty and love of life to varying degrees. 


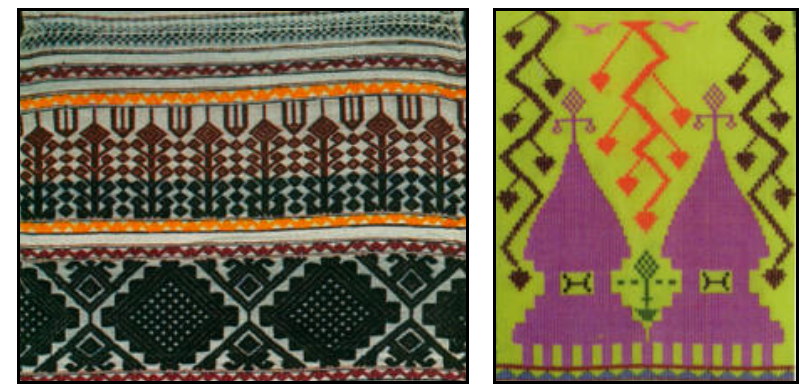

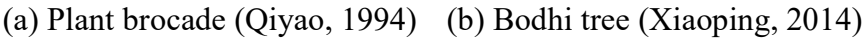

Figure 2. Dai brocade pattern about Plant

\subsubsection{Animal patterns}

In the Dai brocade pattern, what, god horse, beast, elephant trunk, burden elephant, lion, elephant's foot, horn of a cow, chick flower, calf, peacock, golden pheasant, bird's head animal body, chicken paw, bird eye flower, god The rise of animal patterns such as birds has natural environmental factors as well as humanistic environmental factors. The peacocks and elephants are regarded as kind and beautiful mascots by the Dai people that the peacock weavers are used for marriage and festive fabrics. The ancestors of the Dai people worshiped elephants. Therefore, the common elephant patterns include elephant pack pagoda, the elephant pack Buddhist shrine grain, and elephant pavilion pattern. They are of various types and originate from life. They are recorded, depicted and inherited through patterns. Animal Dai pattern like fig-3.

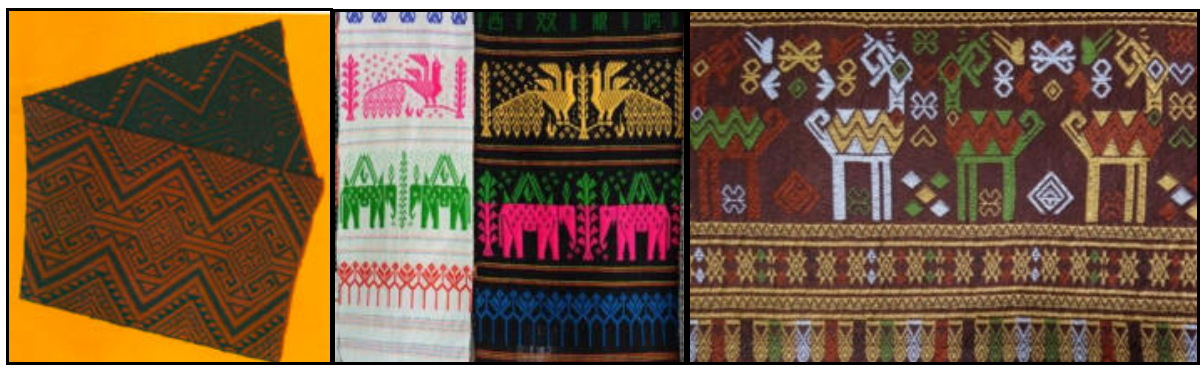

(a) Dai elephant trunk brocade (Qiyao, 1994) (b) God and beast brocade (c) elephant pattern

Figure 3. Dai brocade pattern about Animal

\subsubsection{Person patterns}

The pattern has also experienced the process from "entertaining God" to "entertaining people" since it finally reached the "entertaining people", it will inevitably be indispensable to the social and cultural influence of the "human" subject. The emotion of life is the overall modeling Comprehensive formal experience (Yaohua, 1997). The characters in the Dai brocade image combined with the animal pattern, architecture and other, the cozy residence, comfortable dwelling place, and beautiful living environment and the influence of religious belief, the figures on the brocade are very common. Most of the figures are used in combination with other patterns. It's like an elephant carrying a Buddhist altar, Buddha image in the altar. People stand on horses and canoe on dragon boats etc.

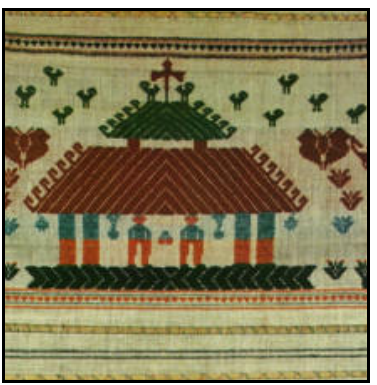

(a) pattern "building and people" (Qiyao, 1994) (

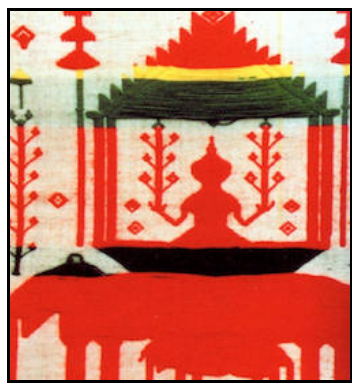

(b) elephant carrying a Buddhist (Qing, 2009)

Figure 4. Dai brocade pattern about Person 


\subsubsection{Geometric patterns}

The geometric pattern is the earliest decorative pattern used by human beings, which appeared in a large suitable number of decorative patterns of colored pottery in the Neolithic age. It has been used to this day through all historical periods. It is the longest-lasting decorative pattern. Differentiation can produce more abstract patterns (Rongrong \& Weidong, 2006). Geometric patterns have the characteristics of simplicity, exquisiteness, and easy production. They are variations in colors and clear in layers. They are popular among the Dai people and are widely used in their lives. The representative geometric patterns in Dai brocade are diamond grain, octagon grain, elephant trunk grain, and horn bend grain. Throughout the composition, dots, lines, faces, blocks, corners and other elements form patterns.

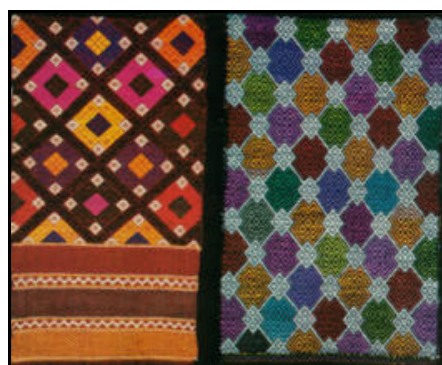

(a) Geometric pattern (Qiyao, 1994)

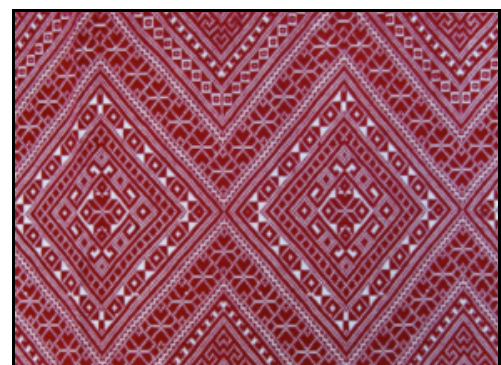

(b) Diamond geometric brocade (Qiyao, 1994)

Figure 5. Geometric patterns about Dai brocade

\subsubsection{Architectural patterns}

The architectural pattern is a special pattern among the brocade patterns. A large number of architectural patterns in brocade, most of them are Buddhist buildings. Such patterns are generally used in Buddhist altars and are mostly used by Buddhist altars and sacrifices. The patterns are exquisite, presented in the form of individual patterns, and the expression methods are relatively realistic and specific. (Figure 6) The Dai ethnic Buddhist embroidered pagoda temple and the Dai ethnic embroidered pagoda temple, the patterns from the top to the bottom represent different building parts in the temple.

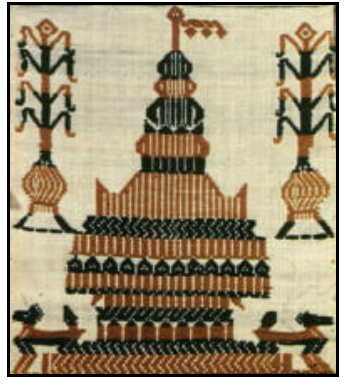

(a)

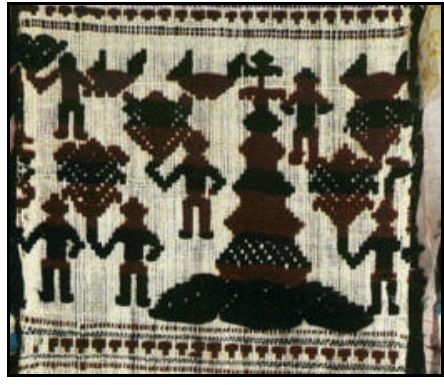

(b) Buddhist pagoda temple (Qiyao, 1994)

Figure 6. Architectural pattern

\subsubsection{Comprehensive patterns}

In the brocade pattern, whether it is figurative or daily life, figures are closely related to the scenes where the Dai people live. The inspiration for the brocade pattern comes directly from life, and it is the people's perception of a better life. The embodiment of life is refined, evolved, imagined and depicted through the scenes of life. As shown in the figure below, the Buddha peacock pattern is a combination of the Buddha pattern and the peacock pattern, which are arranged in a two-square continuous manner, reflecting the distinct local cultural atmosphere. In April 2018, the author visited Dehong Mang City in Yunnan Province and found that many patterns in the brocade pattern are freely matched. They have strong regional color characteristics. Through the choice of colors and themes, they have the brocade patterns with the characteristics of the Dai people, the author classifies these patterns as comprehensive patterns. 

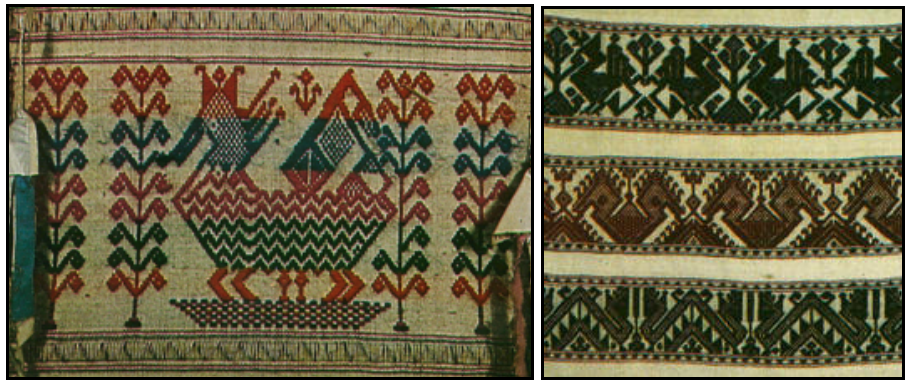

(a) God beast figure

(b Bodhisattva peacock pattern

Figure 7. Dai brocade pattern (Qing, 2009)

Table 1. Classification statistics of Dai nationality brocade

\begin{tabular}{|c|c|c|c|c|}
\hline Theme & Name & $\begin{array}{c}\text { Typical pattern } \\
\text { sketch }\end{array}$ & $\begin{array}{c}\text { Physical } \\
\text { illustration }\end{array}$ & $\begin{array}{l}\text { Implied } \\
\text { meaning }\end{array}$ \\
\hline $\begin{array}{l}\text { Dai brocade } \\
\text { pattern about } \\
\text { Plant }\end{array}$ & $\begin{array}{l}\text { Thorn flower, star } \\
\text { anise flower, ginger } \\
\text { flower, plantain } \\
\text { flower, lotus flower, } \\
\text { etc. }\end{array}$ & Lotus pattern & & $\begin{array}{l}\text { Reappearing the } \\
\text { living } \\
\text { environment and } \\
\text { religion of the } \\
\text { Dai people }\end{array}$ \\
\hline $\begin{array}{l}\text { Dai brocade } \\
\text { pattern about } \\
\text { Animal }\end{array}$ & $\begin{array}{l}\text { God horse, animal, } \\
\text { trunk, elephant } \\
\text { foot, cow corner, } \\
\text { chickens and others }\end{array}$ & $\begin{array}{c}\text { Divine Beast } \\
\text { Pattern }\end{array}$ & & $\begin{array}{l}\text { Love of beauty } \\
\text { and life }\end{array}$ \\
\hline $\begin{array}{l}\text { Dai brocade } \\
\text { pattern about } \\
\text { Person }\end{array}$ & $\begin{array}{l}\text { The figures in Dai } \\
\text { Jin are often } \\
\text { combined with } \\
\text { patterns of animals } \\
\text { and architecture. }\end{array}$ & Chevron pattern & & $\begin{array}{l}\text { Comfortable } \\
\text { living } \\
\text { environment and } \\
\text { religious beliefs }\end{array}$ \\
\hline $\begin{array}{l}\text { Geometric } \\
\text { patterns about } \\
\text { Dai brocade }\end{array}$ & $\begin{array}{l}\text { Diamond pattern, } \\
\text { octagonal pattern, } \\
\text { probosci's pattern, } \\
\text { and horned pattern }\end{array}$ & $\begin{array}{c}\text { Diamond } \\
\text { pattern }\end{array}$ & & $\begin{array}{l}\text { Concise, } \\
\text { exquisite, easy } \\
\text { to produce, with } \\
\text { rich colors and } \\
\text { clear levels }\end{array}$ \\
\hline
\end{tabular}




\begin{tabular}{|c|c|c|c|c|}
\hline $\begin{array}{l}\text { Architectural } \\
\text { pattern }\end{array}$ & $\begin{array}{l}\text { Most of them are } \\
\text { Buddhist buildings, } \\
\text { which are generally } \\
\text { used in Buddhist } \\
\text { altars. Exquisite } \\
\text { patterns, presented } \\
\text { in the form of } \\
\text { individual patterns }\end{array}$ & $\begin{array}{c}\text { Buddhist } \\
\text { architecture }\end{array}$ & 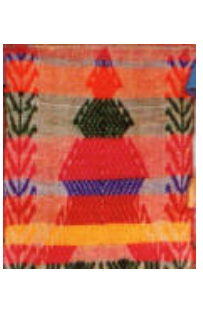 & $\begin{array}{l}\text { Originating from } \\
\text { life, conveying } \\
\text { information } \\
\text { about words, } \\
\text { religion, }\end{array}$ \\
\hline $\begin{array}{l}\text { Comprehensive } \\
\text { patterns }\end{array}$ & $\begin{array}{l}\text { Free combination } \\
\text { of architectural } \\
\text { pattern, geometric } \\
\text { pattern, animal } \\
\text { pattern, plant } \\
\text { pattern, figure } \\
\text { pattern, etc. }\end{array}$ & $\begin{array}{c}\text { flowers and } \\
\text { elephant }\end{array}$ & (IINN & $\begin{array}{c}\text { Free } \\
\text { combination, an } \\
\text { artistic depiction } \\
\text { of life and } \\
\text { decoration }\end{array}$ \\
\hline
\end{tabular}

The unique art form and cultural connotation of the Dai brocade pattern is a reflection of the wisdom and positive attitude of the Dai people. It is also a constant source of inspiration for modern design. The unique ethnic art style, geometric lines and modern sense of the Dai folk pattern are strong. And the color forms have broadened the thinking for the current design and originated from life. So far, people in Xishuangbanna have spread the legend that in the ancient times, "the Dai family on the Lancang River used elephants to plow the fields. The grains were as big as eggs and the ears of grain were as long as oxtails." This reflects the Dai people's love of work, diligent and practical attitude to life, and honesty style. The unique living environment with cultural and historical characteristics of the Dai nationality makes the development of the living features and ethnic style of the Dai nationality patterns inevitable.

\section{The cultural connotation of Dai brocade pattern}

Dai brocade is the concentrated embodiment of Dai culture, which has high aesthetic value, strong breath of life, cultural implication and strong religious color. The cultural connotation of the Dai brocade pattern mainly includes three aspects: "totem worship", "folk custom implication" and "religious culture".

\subsection{Totem Worship}

The worship of animal totems by the Dai people is a direct reflection of the cultural connotation of the brocade pattern. The totem myth is derived from the concept of totems and is used to explain the totem mythology. It mainly uses oral or written forms to describe a living or inanimate creature as a relative, ancestor, or protector; or as an ancestor's benefactor, human being, and creator of all things (Yaohua, 1997). The plants on the brocade and the patterns of the gods and beasts are all reflected in the totem mythology of the Dai people. For example, the idols in Dai mythology have an allegorical meaning. Therefore, elephant patterns are used everywhere in the Buddhist temples of the Dai people Buddha's shrine, for a lifetime of peace and good fortune. The Dai people also have special worship of the dragon. Legend has it that the dragon induced the two "Gongman" gods to evolve into adults and breed offspring to help humans overcome the sinister world. The peacock is the lucky bird of the Dai people and a hope for peace. The Dai people worship elephants, lions, golden deer, peacocks, tigers, phoenixes, and so on. These totems worshipped by the Dai people are fully reflected in the brocade pattern.

\subsection{Folk Custom}

The design of the Dai brocade implies not only the worship of totem but also the expression of local folk customs. For example, "Jinghong" village settled by the Dai people, has superior natural conditions, abundant products, and rich life. To make the village more distinctive, some people have suggested that some representative plants and animals be used as the village's sign. According to the description of the knowledgeable old man, there was a mascot of "meng Jingyong" a long time ago, that is, two kinds of animals, five kinds of trees and six kinds of flowers. Two kinds of animals are peacocks and elephants; five kinds of trees 
are iron pear trees, wood green trees, bay leaves trees, linden trees, olive trees; six kinds of flowers refer to lotus, frangipani, Burmese osmanthus flower, wild ginger flower, phoenix flower, magnolia. Jinghong village is named from the peacock. Every family in the Dai village has planted five trees and six flowers to raise peacocks and elephants. Later, the industrious and intelligent Dai people carved the images of these animals and plants in Buddhist temples, courtyards, water wells, and walls to show their awe. With the development of images such as elephants and peacocks, they have gradually been integrated into the design of Dai brocade. Plants such as five trees and six flowers are also commonly used in the design, adding to the folk meaning of Dai brocade, people's good wishes and yearning for a happy life.

\subsection{Religious culture}

Dai brocade plays an important role in Dai Buddhist culture. It is used to express the devout belief of Buddha in Theravada. Patterns such as linden trees, pagodas, and temples are commonly used on Buddhist altars. The "Streamer" hanging on both sides of the Buddha in the temple is a large-scale work of the brocade. Among the brocades, the Buddhist altar weaved for the Buddhist temple is the product of the most religious color. For example, the sun, moon, clouds, flowers and so on are regarded as the Buddha's seal, which symbolizes the Buddha's dominance of the world. The dragon, the phoenix, the peacock, and the hand patterns are derived from the Buddhist scriptures. The horse, the elephant, the lion, the lotus, the Bodhi are the Buddha Lord Sakyamuni's "birth", " Bodiless", "monasticism", "enlightenment", "speech" and other patterns to praise Buddhism. The Buddhist culture gradually penetrates the life of the Dai people. The brocade is mainly reflected in the combination of Bodhi trees, stupas, Buddhist temples, pavilions, pavilions, auspicious animals and plants, etc., to express the awe and respect of Buddhism. In the development of the Dai nationality for thousands of years, Buddhism has played a great role and influence on the life, culture, aesthetics and historical development of the Dai nationality.

\section{Design and application of Dai brocade pattern in denim dress}

Chinese traditional national culture is extensive, profound and rich in categories. Patterns, as an important part of Chinese traditional culture, have always played an important role in the development of history, reflecting the characteristics of customs in different periods. Every pattern has its own meaning. The embroidered patterns of folk costumes can clearly reflect the local customs, folk customs, aesthetics of religious culture and art (Pan, 2011). As a nation with a history of thousands of years, the Dai people have long formed their unique cultural and artistic forms. The social, economic, cultural structure and even the local customs have unique historical trajectories. In the current ethnic culture, the cultural characteristics of Dai and other ethnic minorities have been repeatedly borrowed and used.

In the evolution of history, denim clothing is constantly innovating and changing, and creating a variety of artistic effects. The unique charm of denim clothing is that it is closely connected with cultural thoughts and values of different periods, and through its own innovative development to meet and lead the consumer demand for clothing fashion at different historical stages (Ling et al, 2013). In the redesign of denim clothing, due to the plasticity, inclusiveness, and abrasion resistance of the fabric itself, there are many creative methods in the design, such as breaking the fabric structure, cutting, tearing, scraping, hollowing out, Physical methods such as drawing, burning, sanding, cutting, pleating, pinching, shrinking, quilting, sewing, and chemical methods such as washing and fading, rotten flowers, and reactive dye printing and dyeing increase the diversity and art of denim clothing fabrics sense. Taking denim and women's clothing as a carrier, the attempt to combine the brocade pattern with modern clothing is precisely due to the plasticity of the second re-design of denim fabric and the diverse design elements of women's clothing, making it easier to find the opportunity for integration between traditional culture and modern design. and realizing the diversification of forms.

\subsection{Simplification of the pattern}

This makes the appearance of the patterns easier and more flexible without losing traditional artistic beauty. The combination with denim fabric is more free and casual, and it is used in the design of modern clothing to have both the national character of fashion sense.

Every nation has the desire and pursuit of self-realization, including modern design, to express its own national characteristics in its own way, to express the nation through tangible entities, and to seek national identity (Ling et al, 2013). The author takes the Dai brocade pattern as the inspiration source of denim dress design, recognizes 
the characteristics of the Dai brocade pattern, and sorts out the design concept, artistic connotation and design elements embodied by Dai brocade pattern. The main method is to break and recombine the traditional patterns, extract representative elements, and retain the basic characteristics and organization of patterns. (figure 8), based on the original Dai brocade patterns, the patterns are decomposed into independent small individuals, and the forms of the design methods are relatively diversified, instead of copying mechanically. This makes the appearance of the patterns easier and more flexible without losing traditional artistic beauty. The combination with denim fabric is more free and casual, and it is used in the design of modern clothing to have both the national character of fashion sense.

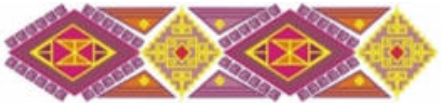

(a)

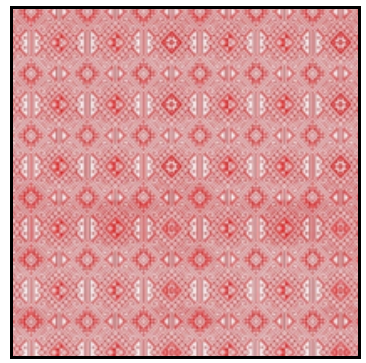

Original pattern of Dai brocade

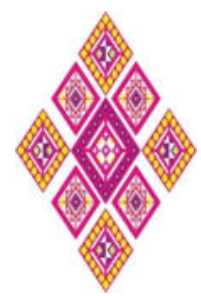

(b)

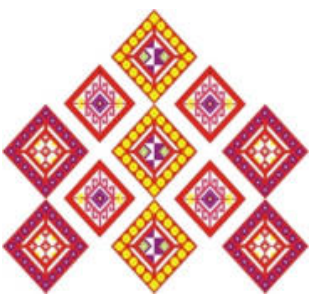

(c)

Pattern element extraction design (by author)

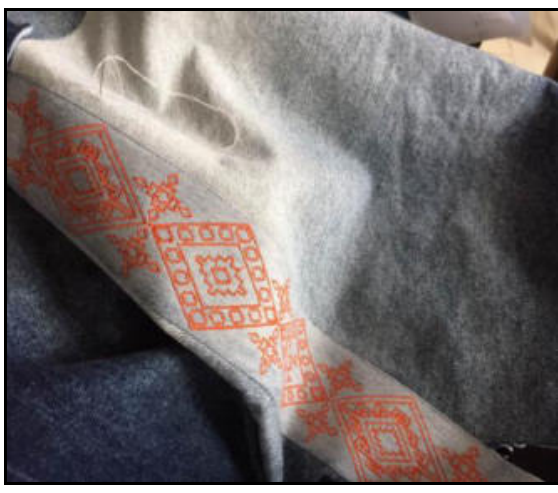

(a)

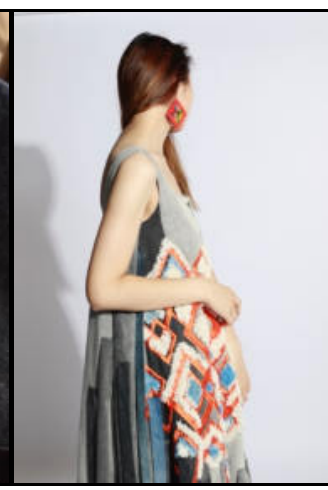

(b)

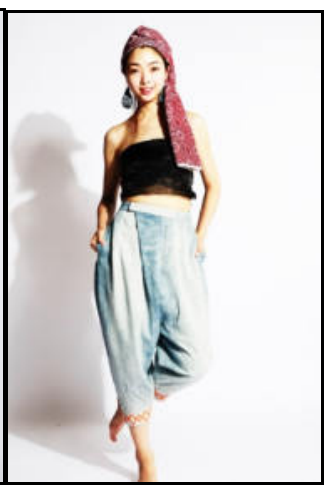

(c)

Figure 8. The application of Dai brocade patterns in fashion design (pattern detail)

The brocade pattern is a kind of non-verbal historical and cultural heritage. It is a mapping of a series of information such as national development, national consciousness, and aesthetic tendencies. It takes the avantgarde denim fabric as a carrier and combines the traditional characteristics of the Chinese nation -- the Dai ethnic-cultural characteristics. Reappearance, modernization, conceptualization, and fashionable, making it a design with Chinese local cultural characteristics, develop into the current popular design concept, and lead a new fashion.

\subsection{Color extraction innovation}

The color itself has no distinction between good, evil, noble, and low. After the projection of national consciousness, it is endowed with a certain meaning, thus forming a symbol, a language, and a representative cultural value (Shuer, 2011). For a long time, the deep-rooted Chinese color is no more than the mainstream 
color of Chinese red and yellow. No matter it is mature commercial propaganda or cultural inheritance, the color with Chinese characteristics on the market mostly adopts these two colors, which makes it a little monotonous in the diversified choice today. Dai brocade pattern is colorful, used primary color, solid color, comparative color, complementary color and so on, to enhance the contrast of color to form a bright, colorful, and highly decorative effect. It has national characteristics without losing the fashion color as inspiration. The brocade pattern is colorful which is clearly contrast with the simple and single color of the denim fabric, but it is also this feature and simple combination that makes it easier to create a sense of coordination in the fusion of elements between traditional and modern so that emerge the beauty of harmony

British fashion designer Hussein Chalayan used Miao Costume as the source of inspiration at his press conference. Black was used as the main color and the colorful Miao ethnic color elements, according to different proportions mix with black. The collision between contrasting and complementary colors and produce a series of strong visual effects, which caused great acclaim in the fashion industry.

And this kind of color matching method is also applicable to the current color matching rules. For example, bright orange, blue, red, earthen yellow, green and orange in Dai brocade are all the colors that can be used for reference. (Figure 9) The orange and blue color extracted from the brocade is the highlight of this denim womenswear design. It is not only the inheritance of traditional culture but also the improvement of the current popular color system.

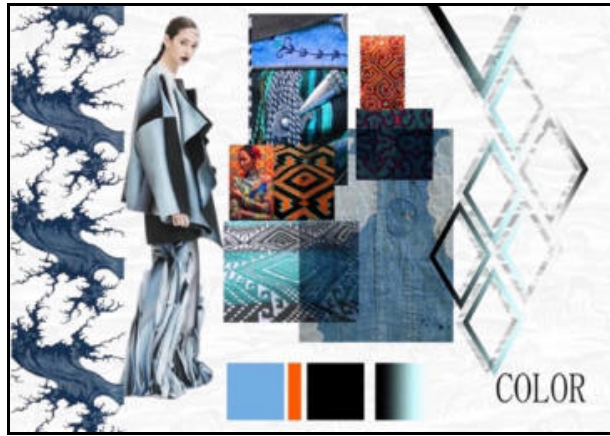

(a) Color inspiration

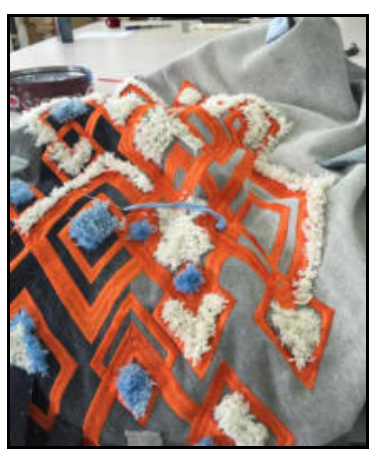

(b) pattern color

Figure 9. Color application of Dai brocade patterns (designed by author)

\subsection{Combination of Forms}

As a very important category in the clothing classification, since the birth of the first denim in the 19th century, it has experienced a century of baptism. It has become a "fashion darling" because of its durability, variability, and wide practicality. This paper attempts to integrate the Dai ethnic brocade designs with denim women's wear, explore the heritage of traditional craftsmanship and fashion beauty, to enhance the diversity of denim women's styles!

In the evolution of history, denim clothing is constantly innovating and changing, creating a variety of artistic effects. The unique charm of denim clothing lies in its close connection with cultural thoughts and values of different periods, through its own innovation and development to meet and lead people's consumption demand for fashion clothing in different historical stages (Ling et al, 2013). In the redesign of denim clothing, due to the plasticity, inclusiveness, and abrasion resistance of the fabric itself, there are many creative methods in the design, such as breaking the fabric structure, cutting, tearing, scraping, hollowing, drawing, burning, grinding, cutting, pleating, pinching, shrinking, quilting, sewing, and other physical methods, as well as washing and fading, burnt-out fabric, reactive dye printing, and other methods, increase the diversity and artistic sense of denim clothing fabrics. Taking denim and women's clothing as the carrier, the attempt to combine the brocade pattern with modern clothing is precisely due to the plasticity of denim fabric reinvention and the diverse design elements of women's clothing, making it easier to find the opportunity for integration between traditional culture and modern design. Achieve formal pluralism.

In the design practice, the author is attempting to take the artistic connotation, composition, and color into consideration and re-design. With the modern aesthetic concepts to simplify the pattern, and break the structure, reorganization. Combined with the embroidery technology for interpretation and expression, the patterns are designed on the cuffs, shoulders, the side parts of clothing, and do the subtraction design, so that they can take the traditional cultural concept and modern design concept to better integrate together (Guodong, 1996). Based 
on the contemporary advanced production level, the profound cultural connotation of Dai pattern, artistic aesthetics, visual symbols and meaning, this paper conducts an in-depth analysis and certification of denim women's clothing, and better integrates the "shape", "color", " manufacturing " and other elements of clothing.

This design work was inspired by the Dai brocade pattern (Figure 10). The author tries to increase the diversity of denim fabric colors through denim washing, with gradient hue in black, white and grey to increase the sense of fashion and uniqueness of the denim fabric. By using physical methods like artistic heading, grinding and shearing to re-design the denim fabric and combined with embroidery and manual sewing to incorporate the redesigned brocade patterns and ethnic concepts into the design of women's denim wear, making the traditional brocades design elements best used in the design. The combination of denim clothing and traditional culture makes the creative value of denim reach the maximum value in a sense.

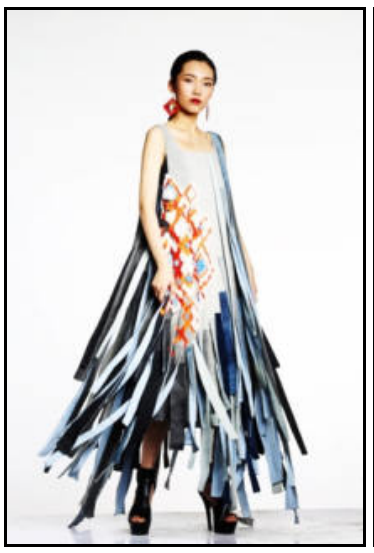

(a)

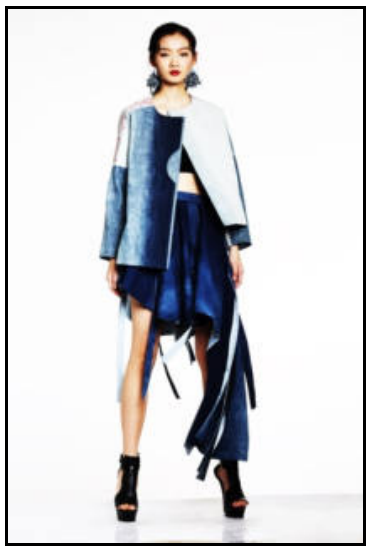

(b)

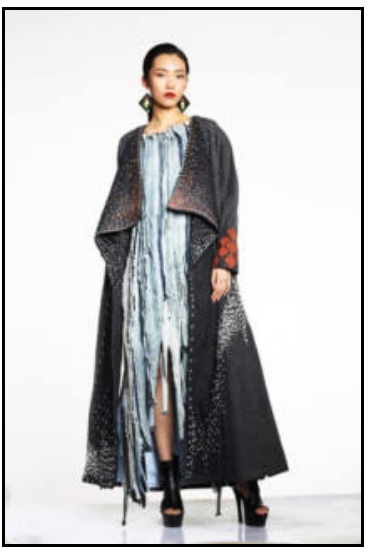

(c)

Figure 10. Innovative design of denim garment under the Dai brocade patterns (designed by author)

\section{Conclusion}

Dai brocade pattern is a very important part of the culture of the Dai people's art and culture. It shows the social development and artistic aesthetics of the Dai people in different periods and provides a valuable cultural treasure for the current design. In today's diversified material culture, what national culture gives us is a unique cultural label and a sign of identity. How to deeply introduce the Broad and profound brocade culture of the Dai nationality into the denim design and how to better integrate the tradition with the modern in the background of ethnic elements is a problem that every designer of us should study diligently.

\section{Reference}

Guodong, D. (1996) Dai history and culture Development Beijing: Ethnic publishing Press.

Ling, G., Wenjun, S. \& Tianhui, Z. (2013) The symbolic value of the color language of Dai costumes. Journal of Zhengzhou light, 14(5), 110-112.

Maolan, Z. Folk art of dyeing and weaving Beijing: China textile press.

Pan, P. (2011) Characteristics and innovative design of denim costume art decoration. Journal of shaanxi university of science and technology, 29(6), 180-184.

Qing, C. (2009) A Study on the Brocade Pattern Art of the Dai People in YunnanKunming University of Science and Technology.

Qiyao, D. (1994) Yunnan folk art Kun Min: Yunnan people's publishing press.

Rongrong, C. \& Weidong, G. (2006) Interpretation of folk meaning in embroidery patterns of folk clothing.

Journal of Textiles, 5, 101-111.

Shuer, T. (2011) The innovative application of Chinese traditional culture in modern costume design. The mass of literature and art, 19.

Xiaoping, Q. (2014) A collection of Chinese brocade. Beijing: China textile press.

Yaohua, L. (1997) General theory of ethnology Beijing: Minzu university of China press.

Yi, Z. \& Yuan, T. (2007) Brocade China society press. 